\title{
Thermodynamic analysis and isothermal bainitic transformation kinetics in lean medium-Mn steels
}

\author{
M. Morawiec ${ }^{1}$ (D) - V. Ruiz-Jimenez ${ }^{2}$. C. Garcia-Mateo ${ }^{2}$ (D) A. Grajcar ${ }^{1}$ (D
}

Received: 1 December 2019 / Accepted: 14 September 2020 / Published online: 9 October 2020

(c) The Author(s) 2020

\begin{abstract}
The work presents the results of thermodynamic analysis of two medium manganese steels with different Mn contents. The steels containing 3.1 and $3.6 \%$ of manganese were subjected to theoretical thermodynamic calculations using MUCG83 software and dilatometric experiments. The steels were heat-treated in two different isothermal holding temperatures of 400 and $350{ }^{\circ} \mathrm{C}$ for $15 \mathrm{~min}$. The bainite transformation kinetics at different temperatures for different manganese contents was investigated. In the steel including 3.1\% Mn, a complete transformation was obtained. The results indicated a strong influence of the holding temperature on the kinetics of bainitic transformation. It was related to the driving force of this process. When the manganese content was increased by $0.5 \%$, an incomplete bainite transformation occurred. The microstructure investigations after heat treatment were performed using light and scanning electron microscopy. The XRD analysis to determine retained austenite amount and its carbon enrichment was performed. The microstructure of $3 \mathrm{MnNb}$ steel consisted of bainite and retained austenite with filmlike and blocky morphologies. The steel with the higher Mn content contained also fresh martensite for both isothermal holding temperatures.
\end{abstract}

Keywords Isothermal bainitic transformation $\cdot$ Medium-Mn steel $\cdot$ Dilatometry $\cdot$ Thermodynamic calculations $\cdot$ Retained austenite

\section{Introduction}

The development of new materials for automotive industry strongly affects various investigations conducted around the world. The design process needs to take into account safety and environmental aspects of car body production. One of the most important factors in car body manufacture is the material price. Medium-Mn steels are dedicated to the automotive sector due to their multiphase structure generating very beneficial properties. These steels are designed to compromise between cost and mechanical properties. Medium-Mn steels should have higher mechanical properties than first generation AHSS but be cheaper than second generation of AHSS (advanced high-strength steels) [1-3].

M. Morawiec

mateusz.morawiec@polsl.pl

1 Department of Engineering Materials and Biomaterials, Silesian University of Technology, 18a Konarskiego Street, Gliwice, Poland

2 National Center for Metallurgical Research, Av. de Gregorio del Amo, 8, 28040 Madrid, Spain
The main structural constituent that gives these steels good formability is retained austenite. This phase undergoes strain-induced martensitic transformation. A local increase in strength accompanying this transformation allows prolonging deformation, which finally leads to higher formability and mechanical properties [4-6]. These aspects allow to implement such steels for cold-rolled steel coils for the automotive application. This approach ensures the formation of retained austenite in a bainite matrix, which can enhance the formability of the steel, increasing the range of possible product applications (especially with the complex shape). That's why the knowledge on phase transformation kinetics of various phases is very important.

To determine phase transitions in metallic materials during heating and cooling a thermal analysis is used. This method gives detailed information on a phase transformation kinetics rate and critical temperatures of different phases in the liquid and solid states [7, 8]. One of them is dilatometry combining a linear thermal expansion principle with phase transformations occurring during heat treatment. This method can be applied during continuous cooling or under conditions of isothermal treatment. For the isothermal bainite transformation, it is 
possible to determine its rate and amount of a formed phase at different temperatures or incubation times. At the same time, austenite stability during cooling to room temperature after the isothermal step may be examined.

Medium-Mn steels are usually investigated in terms of austenite stability upon continuous cooling from an intercritical annealing step performed in an austenite-ferrite region [9, 10]. A few CCT or TTT diagrams for medium-Mn steels can be also found in the literature [11]. However, so far there are no systematic studies on transformation kinetics under conditions of isothermal bainitic transformation. Therefore, the study aims at providing some computational and experimental data on the isothermal bainitic transformation kinetics in two lean medium-Mn steels. The effects of manganese content, isothermal holding temperature and prior martensite presence on the bainite transformation kinetics are addressed.

\section{Experimental}

For the analysis of bainitic transformation kinetics and austenite stability, two different medium manganese steels were investigated. The chemical composition of the steels is presented in Table 1.

The chemical compositions are very similar except a Mn content, which is a basis for steel coding: $3 \mathrm{MnNb}$ and $4 \mathrm{MnNb}$. Both steels include the increased manganese content to stabilize retained austenite. A high aluminum content prevents carbide formation during bainitic transformation leading to higher enrichment of the austenite in carbon.

The thermodynamic analysis was performed using MUCG database ver. 83 software [12] to determine the effect of chemical composition (especially a Mn content) on the phase transformation kinetics for both steels. The heat treatment performed in the dilatometer is presented in Fig. 1.

The samples were heated up to $1100^{\circ} \mathrm{C}$ at a rate of $3{ }^{\circ} \mathrm{C} \mathrm{s}^{-1}$ and kept in this temperature for $300 \mathrm{~s}$ to homogenize austenite microstructure. After this step, the material was cooled at a rate of $60{ }^{\circ} \mathrm{C} \mathrm{s}^{-1}$ to selected isothermal holding temperatures: 400 and $350{ }^{\circ} \mathrm{C}$. The duration of the isothermal step was $900 \mathrm{~s}$. After this step, the samples were cooled down to room temperature at a rate of $1{ }^{\circ} \mathrm{C} \mathrm{s}^{-1}$. These parameters were selected according to theoretical calculations carried out using JMatPro software in another study [13]. According to this study, $60^{\circ} \mathrm{C} \mathrm{s}^{-1}$ ensures no transformation during cooling

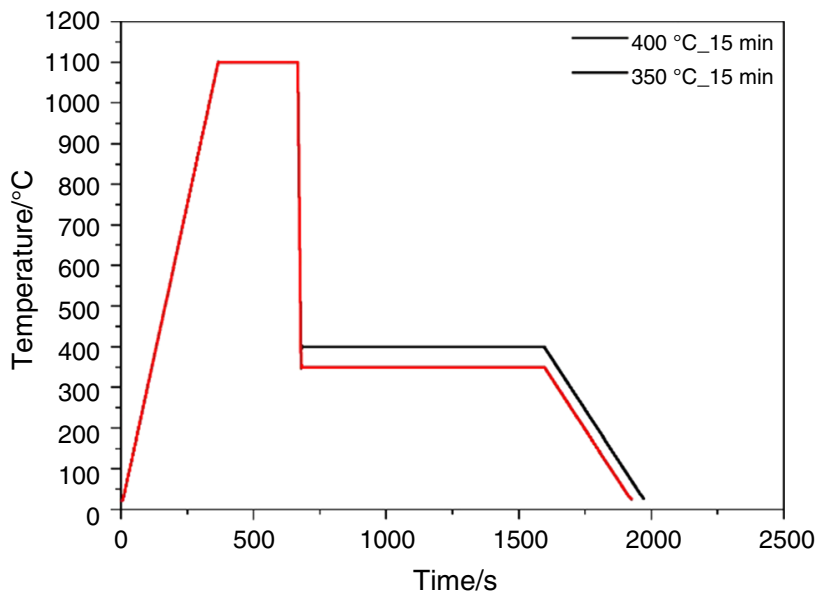

Fig. 1 Heat treatment performed in the dilatometer

to isothermal holding temperature. The 400 and $350{ }^{\circ} \mathrm{C}$ were selected to ensure a bainite formation during the isothermal holding. However, in case of $3 \mathrm{MnNb} 350{ }^{\circ} \mathrm{C}$ treatment, the formation of some martensite is expected (holding below $M_{\mathrm{s}}$ temperature).

All heat treatments were performed on 4-mm-diameter and 10-mm-length cylinders in a BAHR 805A high-resolution dilatometer. Cooling is applied by blowing helium to the sample, which was used as a quenching gas and the temperature was controlled by a type $\mathrm{K}$ thermocouple welded to the central part of the sample surface. The dilatometry test was performed using a specific module, equipped with fused silica push-rods to measure the longitudinal changes during different stages of the heat treatments. From the obtained data, critical transformation temperatures, $A_{\mathrm{c} 1}, A_{\mathrm{c} 3}$ and $M_{\mathrm{s}}$, and the kinetics of bainitic transformation were determined. The specimens were sectioned and polished following conventional metallographic techniques, and the microstructure was revealed by etching with Nital $2 \%$.

$\mathrm{X}$-ray diffraction measurements were carried out with a Bruker AXS D8 diffractometer equipped with a Co X-ray tube. A current of $30 \mathrm{~mA}$ and a voltage of $40 \mathrm{kV}$ were employed as tube settings. XRD data were collected over a $2 \theta$ range of $35^{\circ}-135^{\circ}$ with a step size of $0.01^{\circ}$. To this end, samples were prepared following the standard metallographic procedures finishing with $1 \mu \mathrm{m}$ diamond paste.
Table 1 Chemical compositions of investigated steels

\begin{tabular}{lllllll}
\hline & $\mathrm{C} / \%$ & $\mathrm{Mn} / \%$ & $\mathrm{Si} / \%$ & $\mathrm{Al} / \%$ & $\mathrm{Mo} / \%$ & $\mathrm{Nb} / \%$ \\
\hline $3 \mathrm{MnNb}$ & 0.17 & 3.1 & 0.22 & 1.6 & 0.22 & 0.04 \\
$4 \mathrm{MnNb}$ & 0.18 & 3.6 & 0.23 & 1.7 & 0.20 & 0.04 \\
\hline
\end{tabular}




\section{Results and discussion}

\section{Theoretical calculations}

A first step was theoretical calculations for investigated steels. First, the $T_{0}$ curves (Fig. 2) and driving force for the bainite transformation (Fig. 3) were calculated using a MUCG software [12]. It was done to determine the effects of temperature and manganese content on a driving force of bainite transformation. According to the presented curves, the isothermal holding temperature has an impact on the driving force for bainite transformation. Lowering temperature of this step from 400 to $350{ }^{\circ} \mathrm{C}$ leads to the higher driving force and resulting increase in the amount of bainitic phase. Together with the higher amount of bainite, the carbon enrichment of austenite increases too. This is because bainite dissolves lower amount of carbon compared to austenite. This excess carbon diffuses to austenite increasing its stability. On the other hand, the increase in manganese content gives an opposite result. When manganese content is increased, the $T_{0}$ curve shifts to the left. This means the lower amount of bainite and corresponding smaller carbon enrichment of the austenite. The calculations of the driving force show that a decrease in temperature by $50{ }^{\circ} \mathrm{C}$ increases the driving force by $220 \mathrm{~J} \mathrm{~mol}^{-1}$. In case of manganese, its $0.5 \%$ increase reduces the driving force by $25 \mathrm{~J} \mathrm{~mol}^{-1}$. These results indicate that temperature has a higher impact on the driving force of bainite transformation than a manganese content. However, in case of the analysis for $3 \mathrm{MnNb}$ steel at $350{ }^{\circ} \mathrm{C}$, a martensite transformation needs to be taken into account. On the basis of the martensite start temperature $\left(M_{\mathrm{s}}\right)$ calculation, it was determined that $M_{\mathrm{s}}$ for this steel is $\sim 400{ }^{\circ} \mathrm{C}$. It means that during cooling to isothermal holding temperature of $350{ }^{\circ} \mathrm{C}$, some martensite is formed. This will affect the bainite transformation kinetics [14].

To determine if the calculated carbon enrichment is enough to stabilize austenite to room temperature, the martensite start temperature was determined as a function of carbon content [13]. These results for both steels are presented in Table 2. According to the presented results, one can see that obtained carbon enrichment is not enough to stabilize austenite to room temperature in both cases. The calculations indicate that for $3 \mathrm{MnNb}$ steel, the carbon enrichment of austenite is ca. $1.1 \%$ and for $4 \mathrm{MnNb} \sim 1 \%$. Therefore,
Fig. $2 T_{0}$ curves for investigated steels. Cbulk-amount of carbon in steel

Fig. 3 Curves presenting the driving force for bainite transformation
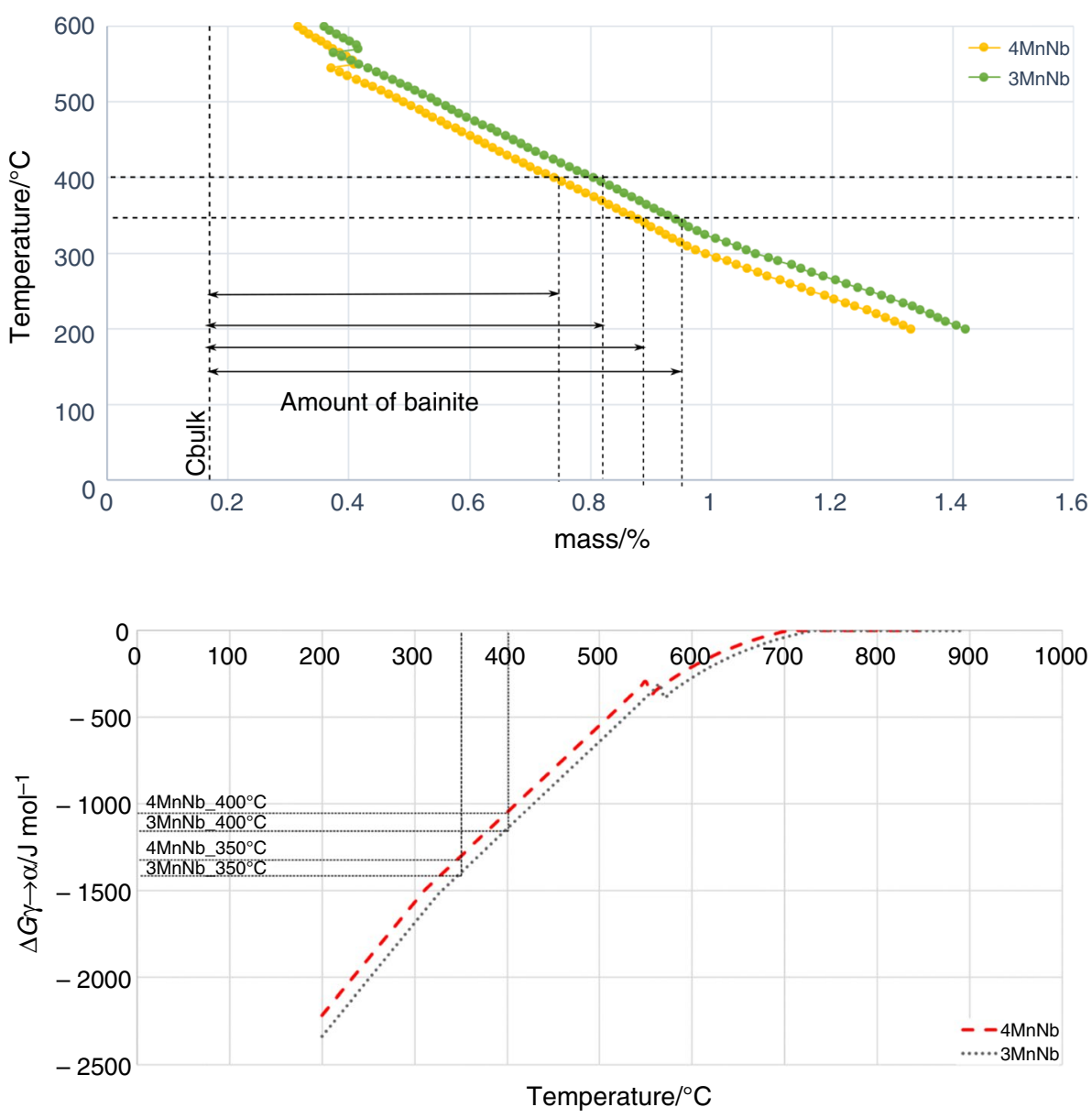
Table 2 Carbon enrichment of the austenite and corresponding $M_{\mathrm{s}}$ temperatures for both steels calculated by MUCG software

\begin{tabular}{lll}
\hline$C \gamma / \mathrm{mass} \%$ & $M_{\mathrm{s}}{ }^{\circ} \mathrm{C} 3 \mathrm{MnNb}$ & $M_{\mathrm{s}} /{ }^{\circ} \mathrm{C} 4 \mathrm{MnNb}$ \\
\hline 0.2 & 387 & 373 \\
0.3 & 335 & 321 \\
0.4 & 289 & 274 \\
0.5 & 245 & 230 \\
0.6 & 198 & 142 \\
0.7 & 125 & 112 \\
0.8 & 112 & 96 \\
0.9 & 65 & 49 \\
\hline
\end{tabular}

some fraction of "fresh" martensite could be formed during cooling to room temperature.

\section{Dilatometric analysis}

After thermodynamic calculations, the dilatometric study was carried out. The tests were performed according to Fig. 1. A first step was to analyze dilatometric curves during heating to determine the repeatability of the tests. Figure 4 presents the curves registered for all heat treatment variants.

According to the dilatometric curves, some differences can be seen. The difference between $3 \mathrm{MnNb}$ and $4 \mathrm{MnNb}$ steels is due to a manganese content. The differences in $4 \mathrm{MnNb}$ steel curves may indicate some segregation of alloying elements. This means that some issues may occur during bainite transformation. Additionally, the $A_{\mathrm{c} 1}$ and $A_{\mathrm{c} 3}$ temperatures for both steels were determined. The austenite transformation for $3 \mathrm{MnNb}$ steel starts at $715^{\circ} \mathrm{C}$ and finishes at $1015^{\circ} \mathrm{C}$. The $4 \mathrm{MnNb}$ steel has a similar starting temperature of $705{ }^{\circ} \mathrm{C}$ but a lower finish transformation temperature of $970{ }^{\circ} \mathrm{C}$. This change in finish temperature is caused by

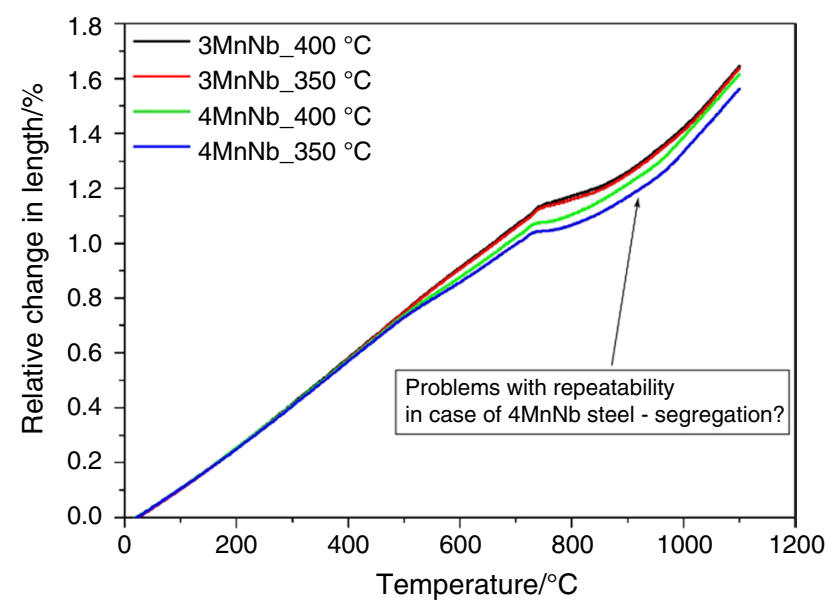

Fig. 4 Dilatometric curves registered during heating for all samples higher manganese content in the $4 \mathrm{MnNb}$ steel. The manganese is an austenite stabilizer [6]. That is why the decrease in $A_{\mathrm{c} 3}$ temperature can be seen [15]. According to the registered results, the selected austenitization temperature was correct.

During cooling to an isothermal holding temperature, only $3 \mathrm{MnNb}$ steel at $350{ }^{\circ} \mathrm{C}$ has a different curve compared to the others (Fig. 5). In this case, a small increase in relative change of length can be seen. This corresponds to a volume increase in samples indicating transformation of some austenite fraction into martensite. This results from the fact that the isothermal holding temperature of $350{ }^{\circ} \mathrm{C}$ is lower than $M_{\mathrm{s}}$ temperature of $3 \mathrm{MnNb}$ steel. The other curves do not indicate any martensite transformation. According to Guo et al. [14], prior martensite formed before an isothermal treatment step has a high impact on the bainitic transformation kinetics. The prior martensite locally deforms the austenite increasing its dislocation density. This changes conditions for nucleation and growth of bainite and decreases the energy required for heterogeneous bainite nucleation. Hence, the higher amount of nucleation sites is present, which influence the incubation and bainitic transformation times. Similar results were obtained by Navarro-Lopez et al. [15]. They also showed that the formation of prior martensite strongly affects the bainite transformation kinetics. When the amount of prior martensite increased, the rate of transformation increased too.

The analysis of isothermal holding step was performed for different temperatures and manganese contents. The dilatometric curves registered during the isothermal step for $3 \mathrm{MnNb}$ steel are presented in Fig. 6a.

First thing that may be seen is that at $400{ }^{\circ} \mathrm{C}$, a higher signal from bainitic transformation was obtained. The reason for this may be a smaller amount of austenite transformed into bainite at $350{ }^{\circ} \mathrm{C}$ due to martensite formation. In the

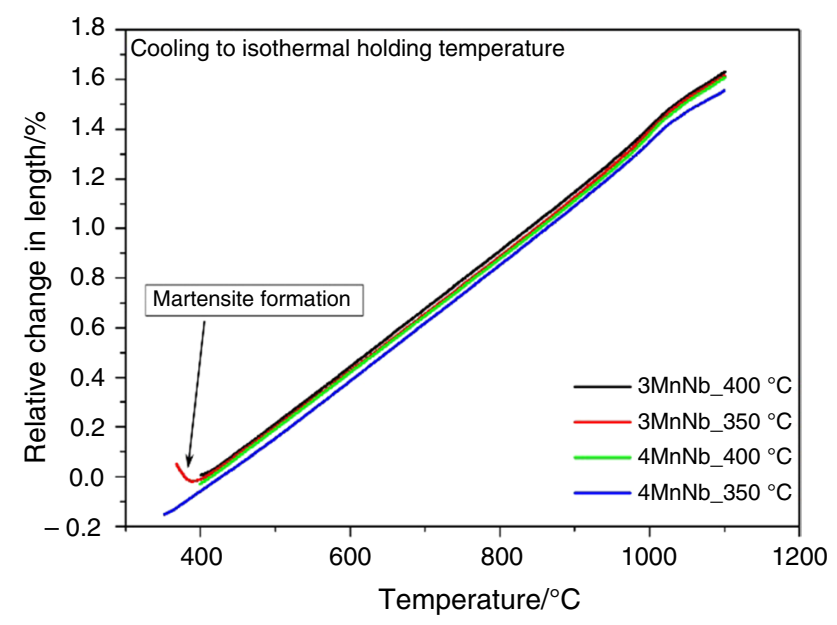

Fig. 5 Dilatometric curves registered during cooling to isothermal holding temperature 

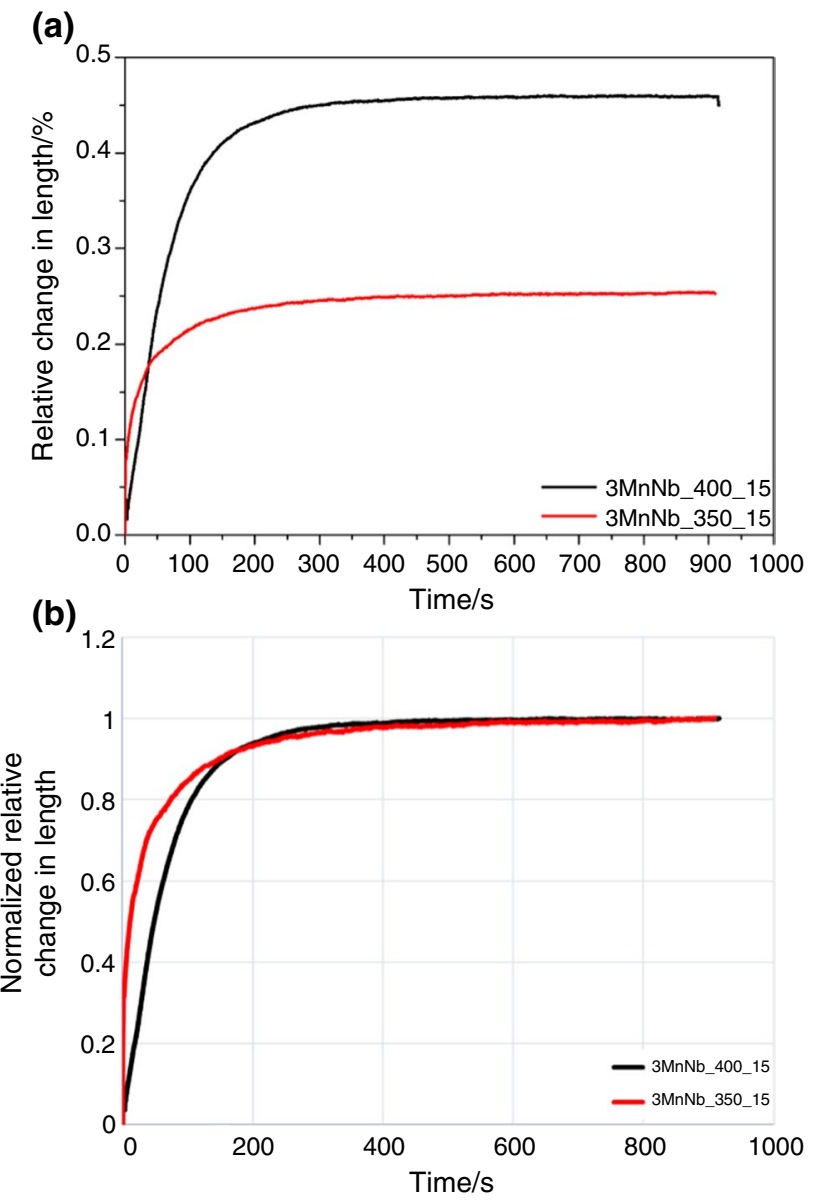

Fig. 6 Isothermal holding step for $3 \mathrm{MnNb}$ steel: a dilatometric results, b normalized curve

research of Navarro-Lopez et al. [15], the authors showed that the formation of prior martensite decreased the amount of bainite created during the isothermal step. Moreover, the prior martensite undergoes tempering resulting in carbon diffusion from martensite to austenite. The diffusion led to contraction, which affects a level of signal at $350{ }^{\circ} \mathrm{C}$. In both cases, the transformation was finished after $10 \mathrm{~min}$. This means that a carbon enrichment of the austenite was high enough to be in equilibrium with bainite (amount of carbon in $T_{0}$ curve). No further carbon enrichment of austenite is possible for this steel. Moreover, a difference in bainitic transformation rate can be seen. The $350{ }^{\circ} \mathrm{C}$ sample has the higher transformation rate (Fig. 6b) compared to $400{ }^{\circ} \mathrm{C}$, especially at the beginning of bainite transformation. The reason for this fact is mentioned prior martensite created before the isothermal step. The martensite locally deforms the austenite resulting in the higher amount of nucleation places for bainite transformation [14, 16]. This accelerates the rate of bainite formation at this temperature. There is no incubation time for both isothermal holding temperatures. This is because of high aluminum content of the steel (1.6\%).

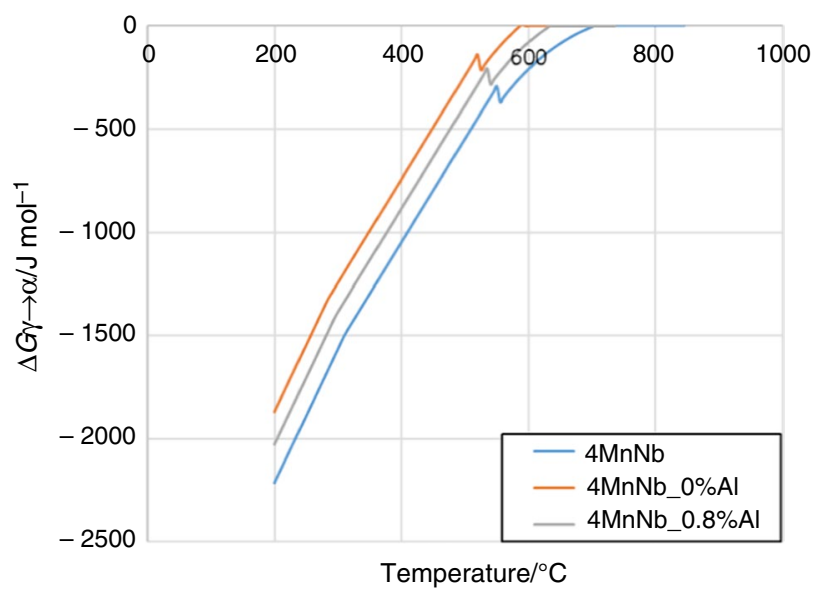

Fig. 7 Theoretical calculations of aluminum effect on the driving force of bainite transformation

Because $\mathrm{Al}$ is an $\alpha$ phase stabilizer, it increases the driving force for bainite transformation as presented in Fig. 7. The figure presents the results of $\mathrm{Al}$ addition on a driving force of bainite transformation for different $\mathrm{Al}$ contents. The calculations included three aluminum contents: $0,0.8$ and $1.6 \%$. The high aluminum content in steel increases the driving force, which accelerates the transformation significantly. The difference in driving force between 0 and $1.6 \%$ of $\mathrm{Al}$ is $306 \mathrm{~J} \mathrm{~mol}^{-1}$. This is the reason for a lack of incubation time for both samples. A similar conclusion reached Tian et al. [17], who investigated the influence of $\mathrm{Cr}$ and $\mathrm{Al}$ on the bainite transformation. The bainite transformation in their case was faster in steel with the addition of aluminum. Similarly, according to Caballero and Bhadeshia [18], aluminum increases the driving force for the transformation of austenite into bainite, which leads to a higher transformation rate.

The last step of the heat treatment after isothermal holding was cooling to room temperature. Results are presented in Fig. 8. In both cases, during cooling to room temperature no fresh martensite was formed. This means that the carbon enrichment of the austenite was high enough to stabilize it to room temperature. It is true even though theoretical calculations show that the level of enrichment should not be enough.

The results for $4 \mathrm{MnNb}$ isothermal holding step are presented in Fig. 9. The dilatometric curves show a bainite transformation kinetics at 400 and $350{ }^{\circ} \mathrm{C}$. One can see an incomplete bainite transformation for both temperatures. In both cases, the bainite transformation is not finished within $15 \mathrm{~min}$. It means that $\gamma$ to $\alpha$ equilibrium was not obtained. Therefore, the carbon enrichment of the austenite is not sufficient and some fresh martensite should be expected during cooling to room temperature. 


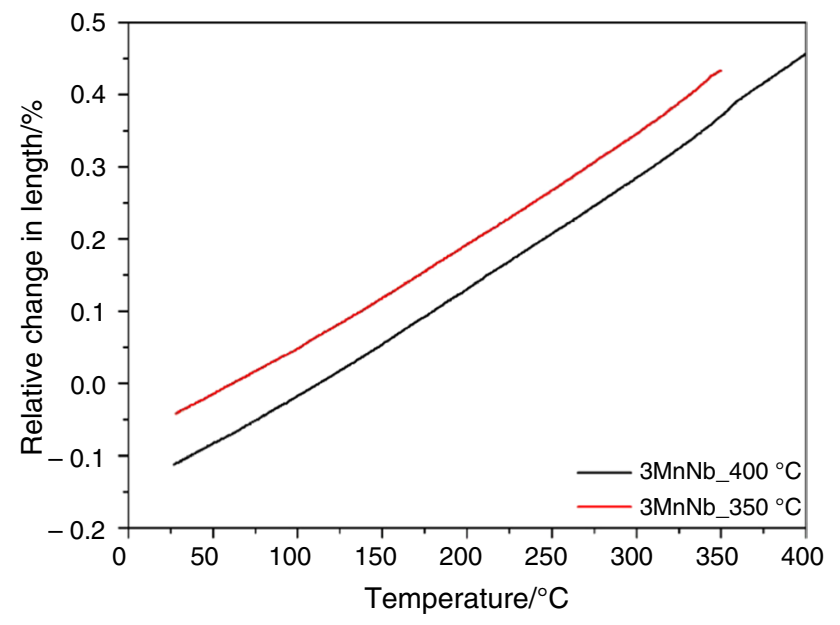

Fig. 8 Dilatometric curves registered during cooling to room temperature

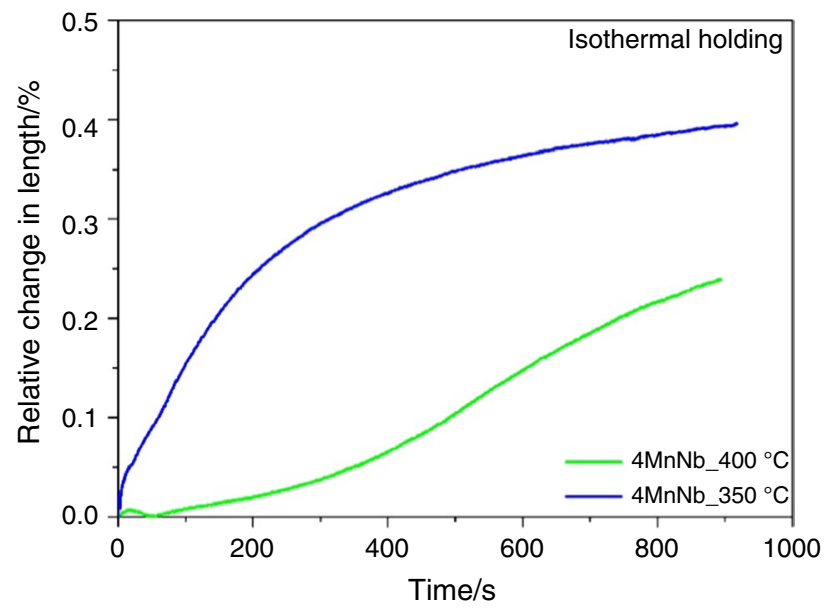

Fig. 9 Dilatometric curves of the isothermal step of $4 \mathrm{MnNb}$ steel registered at 350 and $400{ }^{\circ} \mathrm{C}$

In case of $400{ }^{\circ} \mathrm{C}$, an incubation time is visible. It means that manganese has a strong impact on the bainite transformation kinetics. Manganese influences the transformation by shifting its region in a TTT curve to longer time. That's why an incubation and incomplete transformation take place. Similar results are presented in the work of Guo et al. [19], which reported that manganese retards the bainite transformation. In their case, an increase of $0.5 \% \mathrm{Mn}$ led to two times longer incubation time and a lower transformation rate. According to Farahani et al. [20], who carried out theoretical calculations of $\mathrm{Si}$ and $\mathrm{Mn}$ effects on a bainite amount, manganese decreases the amount of bainite that can be obtained. The reason for this is a high value of dissipation of Gibbs energy caused by interfacial diffusion of $\mathrm{Mn}$. This is in accordance with the presented results. The
$4 \mathrm{MnNb}$ steel needs longer time to complete bainite transformation, and the transformation rate is lower compared to the $3 \mathrm{MnNb}$ steel. When the temperature was decreased to $350{ }^{\circ} \mathrm{C}$, the driving force for the transformation increased. The result of this is a higher dilatometric signal during this step. The higher driving force means more bainite, which in turn causes a higher carbon enrichment of the austenite. In this case, a higher stability of austenite should be expected (a lower amount of fresh martensite during cooling to room temperature).

When looking at Fig. 9, one can see a contrary conclusion. According to the theory, lowering the isothermal holding temperature should increase the incubation time and signal from the bainite transformation. The higher signal is present but the incubation is not observed. The explanation is a small amount of martensitic phase before the isothermal step. The amount is so low that there is no visible signal on a dilatometric curve during cooling to isothermal holding. However, the amount is enough to accelerate the kinetics, which is visible at the beginning of bainite transformation. The formation of martensite could occur because of segregation issues detected by dilatometry. According to Grajcar et al. [21], some segregation may occur in medium-Mn steels. Based on this research, a calculation of martensite start temperature was carried out to determine the possible difference in $M_{\mathrm{s}}$ temperature of these steels. According to this calculation, the maximum difference between lowest and highest $M_{\mathrm{s}}$ temperature was $50{ }^{\circ} \mathrm{C}$. This could explain the theory of small amount of martensite present before the isothermal step, which accelerates the bainitic transformation.

During cooling to room temperature, the transformation of fresh martensite could be detected (Fig. 10). The bigger signal at $400{ }^{\circ} \mathrm{C}$ corresponded to a lower amount of bainite formed during the isothermal step (Fig. 9). This leads to

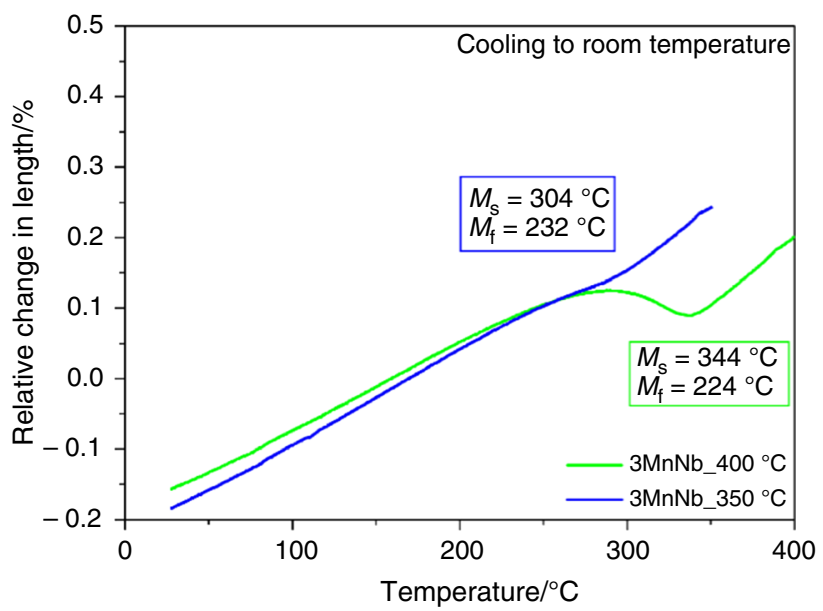

Fig. 10 Dilatometric curves registered during cooling of samples to room temperature 
lower carbon enrichment and corresponding lower thermal stability of austenite. This is indicated also by the $M_{\mathrm{s}}$ temperature. For the lower thermal stability, a higher martensite start temperature is expected. When the temperature was lowered, the amount of bainite increased. An increase in carbon content of the austenite (higher thermal stability) directly decreases the $M_{\mathrm{s}}$ temperature. According to this result, the selected time was too short to fully stabilize the austenite at room temperature.

\section{Microstructure investigation}

After the dilatometric study, the microstructure analysis was carried out. The microstructure presented in Fig. 11 shows the occurrence of segregation bands for all samples. These results are in accordance with the dilatometric analysis during heating to austenitization temperature. In case of $4 \mathrm{MnNb}$ steel, this can prove that there is a possibility of locally higher $M_{\mathrm{s}}$ temperature. Similar conclusion was reported in [15]. The authors stated that banding occurs due to manganese segregation, which created high-Mn and low-

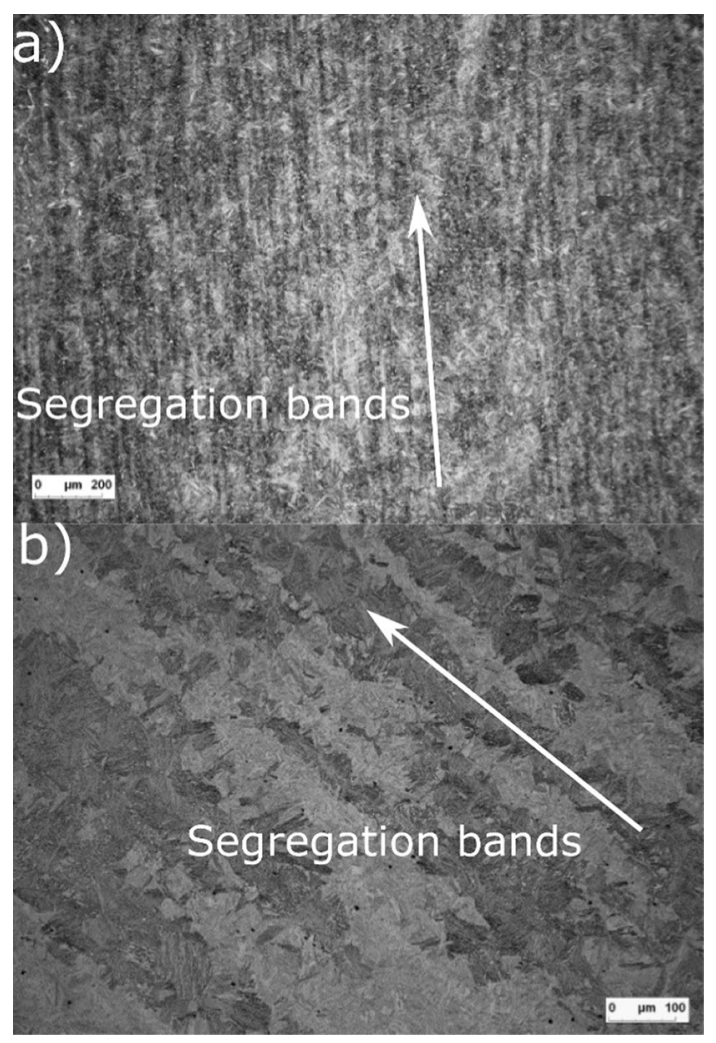

Fig. 11 Segregation bands in the microstructure after heat treatment at $400{ }^{\circ} \mathrm{C}$ : a $3 \mathrm{MnNb}, \mathbf{b} 4 \mathrm{MnNb}$

Mn regions. These areas have different local $M_{\mathrm{s}}$ temperatures and may form small amounts of martensite, which influence the bainitic transformation kinetics as explained earlier.
Figures 12 and 13 show microstructures of $3 \mathrm{MnNb}$ steel processed at different temperatures of isothermal holding. At $400{ }^{\circ} \mathrm{C}$, a fine-grained microstructure composed of bainite and retained austenite can be seen in Fig. 12a. A more detailed micrograph taken using scanning electron microscopy (Fig. 12b) shows that a small amount of martensitic-austenitic islands (MA) is also present. The lack of detection of martensitic transformation by a dilatometer indicates its small amount. The retained austenite in the microstructure takes shape of thin layers between bainitic laths. This morphology positively influences its thermal stability. According to Xiaochuan et al. [22], this kind of morphology strongly stabilizes retained austenite. In this work, two types of retained austenite were present. The first type was characterized by a blocky microstructure. In the second case, the film shape was visible. The filmlike retained austenite had approximately two times lower carbon content, yet it was stable to room temperature. The authors proposed two explanations for this phenomenon. The first one was the presence of martensite near retained austenite. This hard

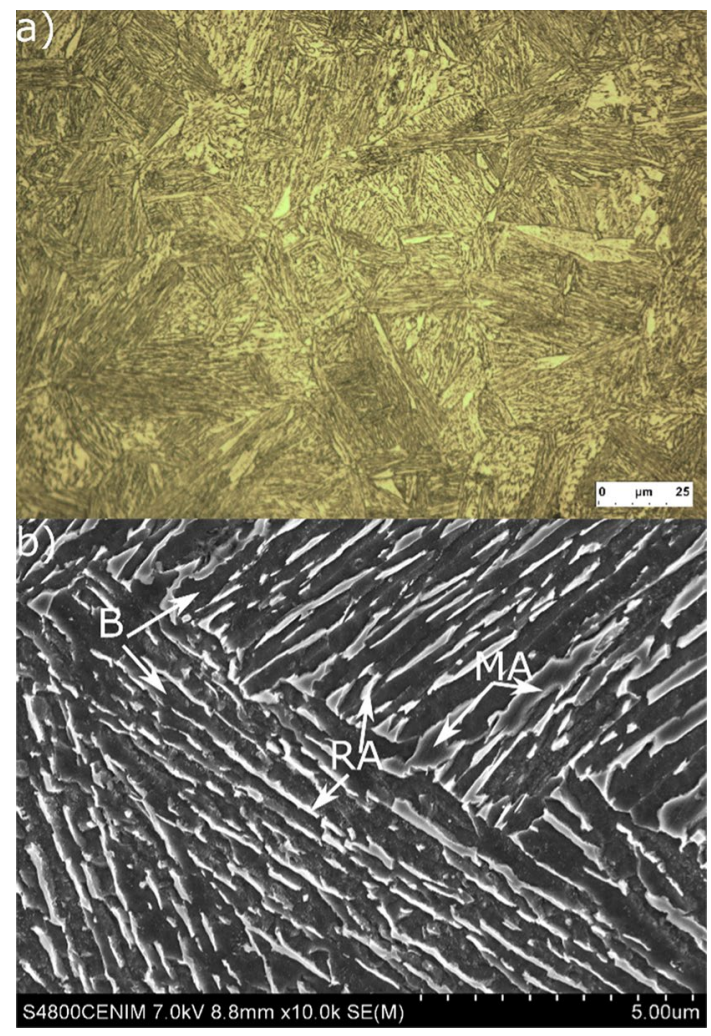

Fig. 12 Microstructure of $3 \mathrm{MnNb}$ steel after isothermal holding at $400{ }^{\circ} \mathrm{C}$ : a light microscope, b scanning electron microscope. $B$ bainite, $M A$ martensitic-austenitic island, $R A$ retained austenite

phase due to its high strength inhibits further martensitic transformation blocking the possibility of austenite expansion (this is a kind of physical stabilization of austenite). 


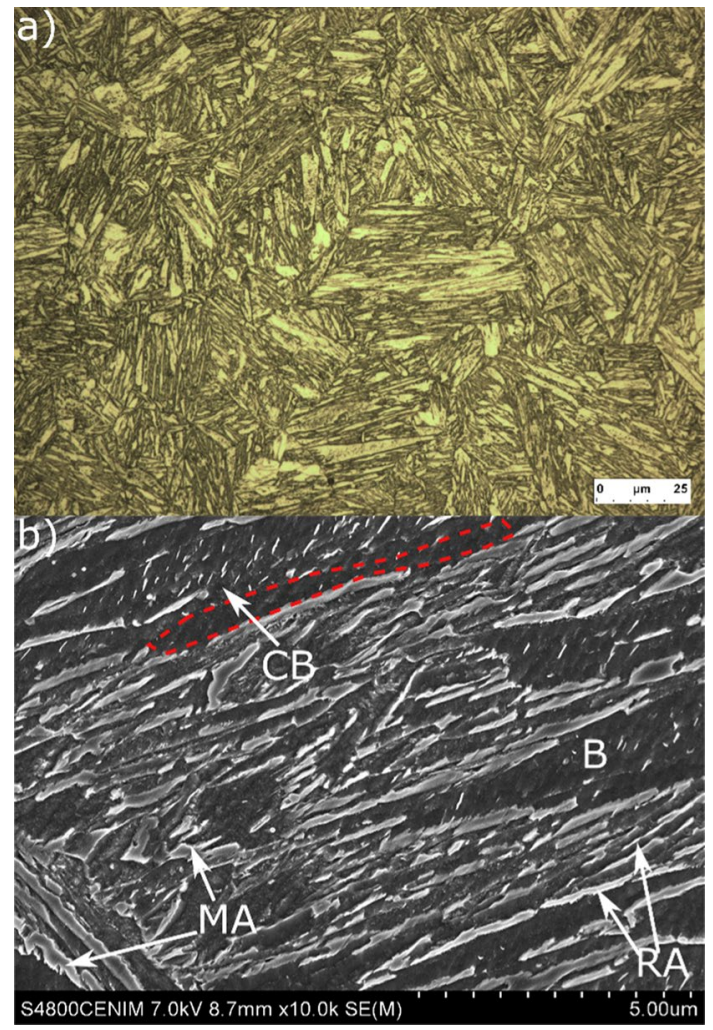

Fig. 13 Microstructure of $3 \mathrm{MnNb}$ steel after isothermal holding at $350{ }^{\circ} \mathrm{C}$ : a light microscope, $\mathbf{b}$ scanning electron microscope. $B$ bainite, $C B$ coalesced bainite, $M A$ martensitic-austenitic island, $R A$ retained austenite

The other possibility was exerted by residual stresses, which create hydrostatic pressure on the retained austenite. The hydrostatic pressure prevents expansion, thus hindering martensitic transformation. In the current work, the second theory is more presumable because the higher transformation kinetics leads to higher residual stresses [20].

At $350{ }^{\circ} \mathrm{C}$, the microstructure is composed of bainite, some amount of tempered martensite and retained austenite (Fig. 13a). In case of bainite plates formed at $350{ }^{\circ} \mathrm{C}$, their bigger thickness and higher amount can be observed compared to $400{ }^{\circ} \mathrm{C}$. These differences result from the increased driving force of bainitic transformation at this temperature. A higher magnification analysis (Fig. 13b) shows the higher amount of bainite and its bigger plate thickness. Moreover, the bainite has two types. The major one is lath bainite and the second one is coalesced bainite. The second type of bainite is characterized by precipitate free zone (marked in red in Fig. 13b). It is formed at the beginning of transformation stage by coalescence of bainite plates [23]. According to Bhadeshia et al. [24], the coalesced bainite is created by dissolution of filmlike austenite, which is present at bainite grain boundaries. This leads to a growth of bainite plate thickness by merging process of thin plates. The excess
Table 3 Amount of phases and retained austenite carbon enrichment at different isothermal holding temperatures of $3 \mathrm{MnNb}$ steel

\begin{tabular}{llll}
\hline & $\begin{array}{l}\text { Amount of } \\
\gamma_{\mathrm{r}} / \%\end{array}$ & $\begin{array}{l}\text { Amount of car- } \\
\text { bon in } \gamma_{\mathrm{r}} / \text { mass } \%\end{array}$ & Amount of $\alpha / \%$ \\
\hline $3 \mathrm{MnNb}-400^{\circ} \mathrm{C}$ & 13 & 0.92 & $87=\alpha_{\mathrm{b}}$ \\
$3 \mathrm{MnNb}-350^{\circ} \mathrm{C}$ & 11 & 1.06 & $89=\alpha_{\mathrm{b}}+\alpha^{\prime}$ \\
\hline
\end{tabular}

carbon from the dissolved austenite can precipitate in a central part of bainite as cementite or undergo partitioning to retained austenite. Because the coalesced bainite plates are very thick this partitioning may occur only at $\gamma / \alpha$ borders. That's why the cementite precipitation inside bainite is more common. This is the reason for precipitate-free zones in coalesced bainite. Authors also observed that the coalesced bainite is present during isothermal heat treatments performed at temperatures lower than $400{ }^{\circ} \mathrm{C}$ [25]. The reason for this is a driving force necessary for the transformation in presence of strain energy associated with the bainite transformation. Larger plates exhibit the higher deformation energy, which need a sufficiently large driving force to growth. That's why the coalesced bainite is not present at $400{ }^{\circ} \mathrm{C}$. At this temperature, the driving force is too low for plates' coalescence.

In case of $350{ }^{\circ} \mathrm{C}$, the retained austenite is present both as thin layers and MA constituents. According to the XRD analysis (presented in Table 3 ), the amount of retained austenite is higher at $400{ }^{\circ} \mathrm{C}$ than at $350{ }^{\circ} \mathrm{C}$. This is due to prior martensite formation before an isothermal step. The martensite transformation reduces the amount of austenite which may undergo bainite transformation. Normally without the martensite, a higher amount of retained austenite is expected at $350{ }^{\circ} \mathrm{C}$. Moreover, one can see that a carbon enrichment of the austenite is higher at $350{ }^{\circ} \mathrm{C}$, which is in accordance with theoretical calculations (the higher driving force). According to the obtained results, the carbon concentration in austenite is higher compared to the calculations.

For $4 \mathrm{MnNb}$ steels, the microstructure is composed of bainite, fresh and tempered martensite and retained austenite. Figure 14 presents the microstructure of $4 \mathrm{MnNb}$ steel at $400{ }^{\circ} \mathrm{C}$. In this case, the microstructure is slightly different compared to $3 \mathrm{MnNb}$ steel. The main difference is the presence of fresh and tempered martensite. The fresh martensite is formed during cooling to room temperature, and at the same time, it undergoes tempering.

The tempered martensite comes from the fresh martensite formed at the beginning of transformation. This martensite is influenced by temperature for the longest time, and some tempering effect occurs during cooling to room temperature. Another difference is retained austenite morphology. In this treatment, the retained austenite is mainly present as blocks and MA constituents. Due to the martensite presence, it is 


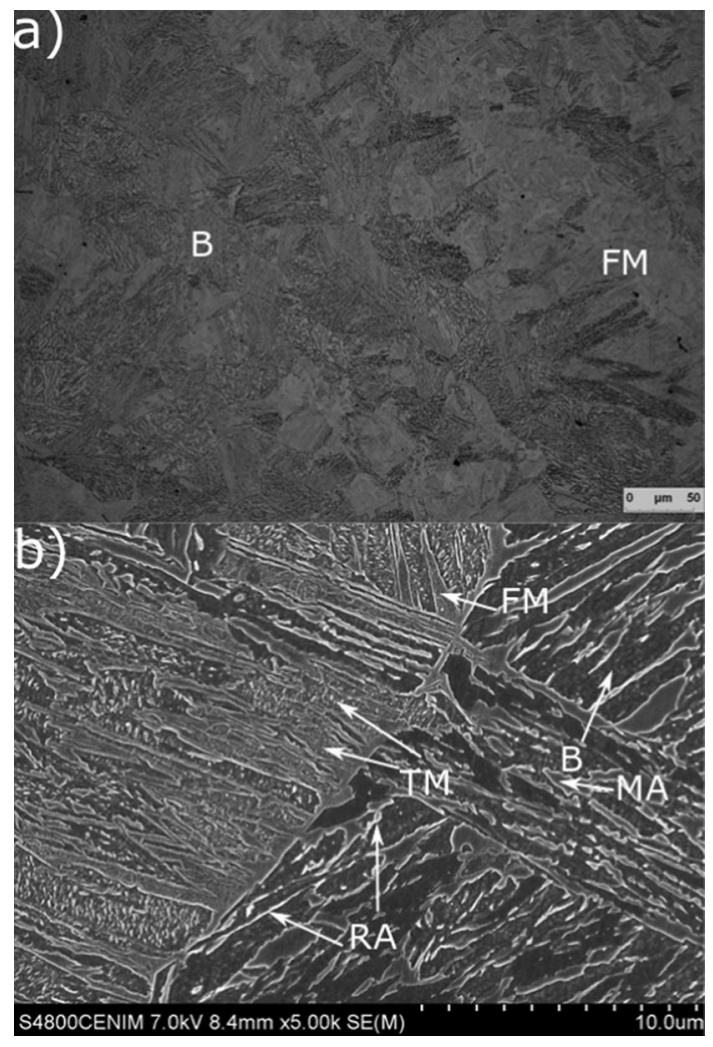

Fig. 14 Microstructure of $4 \mathrm{MnNb}$ steel after isothermal holding at $400{ }^{\circ} \mathrm{C}$ : a light microscope, b scanning electron microscope. $B$ bainite, $M$ martensite, $T M$ tempered martensite, $M A$ martensiticaustenitic island, $R A$ retained austenite

hard to determine the exact amount of bainite formed during isothermal holding at different temperatures. That is why the amount of $\alpha$ phases (bainite and fresh martensite) is listed together in Table 4.

At $350{ }^{\circ} \mathrm{C}$, the microstructure (Fig. 15) is similar to that obtained at $400{ }^{\circ} \mathrm{C}$. According to the dilatometry, a smaller fraction of fresh martensite should be expected. In this temperature, a tempered martensite can be seen. Because the $M_{\mathrm{s}}$ temperature in this case was lower by $40{ }^{\circ} \mathrm{C}$, the martensite undergoes tempering for shorter time. That's why the visible effects are stronger at $400{ }^{\circ} \mathrm{C}$. Similarly to $3 \mathrm{MnNb} 350{ }^{\circ} \mathrm{C}$ treatment, the coalesced bainite is also present. The retained austenite is located in MA constituents and as thin layers between bainite laths. Blocky retained austenite occurs too. According to the XRD analysis of the $4 \mathrm{MnNb}$ steel (Table 4), the retained austenite amount was higher in a sample isothermally treated at $350^{\circ} \mathrm{C}$. This is due to higher driving force of bainite transformation (hence a higher carbon enrichment of austenite). The measured carbon concentration in retained austenite proves this statement. An amount measured for $4 \mathrm{MnNb}$ is lower compared to $3 \mathrm{MnNb}$ steel. This is according to $T_{0}$ curves showing that manganese shifts the curve to the left (to a lower carbon enrichment). At the
Table 4 Amount of phases and retained austenite carbon enrichment at different isothermal holding temperatures of $4 \mathrm{MnNb}$ steel

\begin{tabular}{llll}
\hline & $\begin{array}{l}\text { Amount of } \\
\gamma_{\mathrm{r}} / \%\end{array}$ & $\begin{array}{l}\text { Amount of car- } \\
\text { bon in } \gamma_{\mathrm{r}} / \text { mass } \%\end{array}$ & Amount of $\alpha / \%$ \\
\hline $4 \mathrm{MnNb}-400^{\circ} \mathrm{C}$ & 10 & 0.84 & $90=\alpha_{\mathrm{b}}+\alpha^{\prime}$ \\
$4 \mathrm{MnNb}-350^{\circ} \mathrm{C}$ & 13 & 0.90 & $87=\alpha_{\mathrm{b}}+\alpha^{\prime}$ \\
\hline
\end{tabular}

same time, the amount of retained austenite at $400{ }^{\circ} \mathrm{C}(10 \%)$ is the lowest of all treatments. A lower temperature results in a higher amount of retained austenite $(\sim 13 \%)$, which is the same amount as for the $3 \mathrm{MnNb}$ steel at $400{ }^{\circ} \mathrm{C}$.

\section{Conclusions}

A temperature and a manganese content have a high

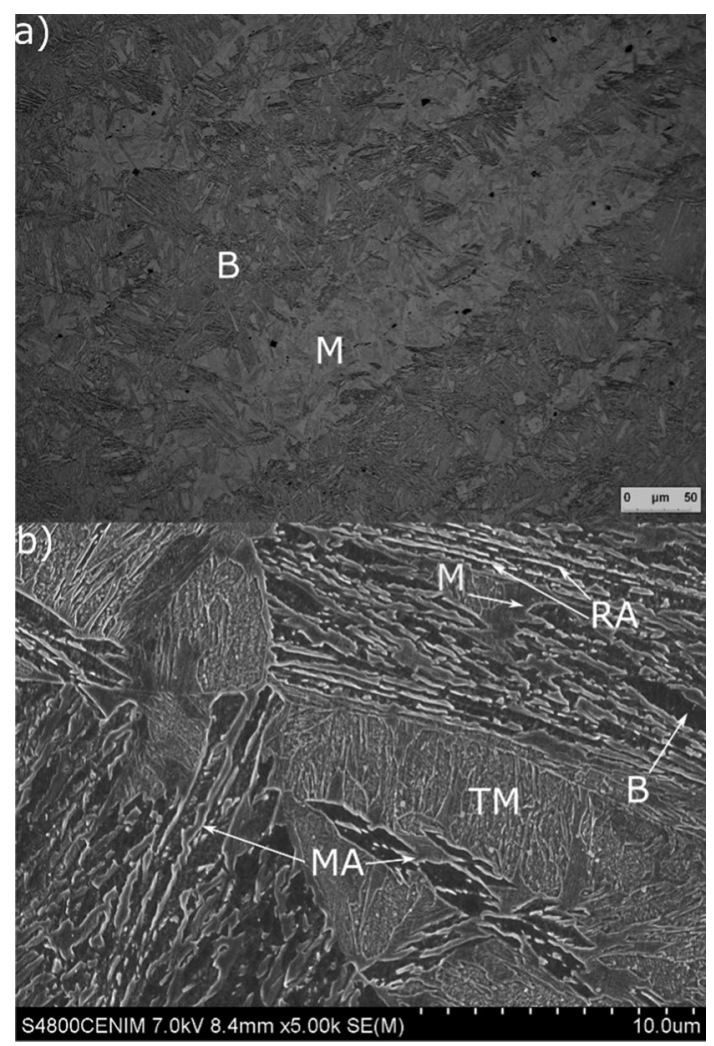

Fig. 15 Microstructure of $4 \mathrm{MnNb}$ steel after isothermal holding at $350{ }^{\circ} \mathrm{C}$ : a light microscope, b scanning electron microscope. $B$ bainite, $M$ martensite, $T M$ tempered martensite, $M A$ martensiticaustenitic constituents, $R A$ retained austenite

impact on the isothermal bainitic transformation kinetics in lean medium-Mn steels. At $350{ }^{\circ} \mathrm{C}$, a higher amount of bainite is formed during the isothermal step due to the 
increased driving force of the transformation. The higher amount of bainite stimulates an increase in carbon content of the austenite increasing its thermal stability and corresponding volume fraction. The manganese content has an opposite effect. The increase of $0.5 \% \mathrm{Mn}$ decreases the driving force of the bainitic transformation. The transformation kinetics is slower due to a retarding effect of $\mathrm{Mn}$ resulting in longer time necessary to finish bainitic transformation.

Martensite formed before an isothermal step also affects the bainite transformation kinetics. The martensite deforms the austenite increasing its dislocation density. The acceleration of bainitic transformation kinetics occurs due to the higher amount of places for bainite nucleation. This effect is present for $3 \mathrm{MnNb}$ steel treated at $350{ }^{\circ} \mathrm{C}$. As the dilatometry showed the transformation kinetics was faster compared to the sample without martensite.

Acknowledgements This work is supported by own scholarship fund of Silesian University of Technology in 2019.

Open Access This article is licensed under a Creative Commons Attribution 4.0 International License, which permits use, sharing, adaptation, distribution and reproduction in any medium or format, as long as you give appropriate credit to the original author(s) and the source, provide a link to the Creative Commons licence, and indicate if changes were made. The images or other third party material in this article are included in the article's Creative Commons licence, unless indicated otherwise in a credit line to the material. If material is not included in the article's Creative Commons licence and your intended use is not permitted by statutory regulation or exceeds the permitted use, you will need to obtain permission directly from the copyright holder. To view a copy of this licence, visit http://creativecommons .org/licenses/by/4.0/.

\section{References}

1. Speer J, Rana R, Matlock D, Glover A, Thomas G, De Moor E. Processing variants in medium-Mn steels. Metals. 2019. https:// doi.org/10.3390/met9070771.

2. Lee YK, Han J. Current opinion in medium manganese steel. Mater Sci Technol. 2015. https://doi.org/10.1179/1743284714 Y.0000000722.

3. Xiong ZP, Kostryzhev AG, Saleh AA, Chen L, Pereloma EV. Microstructures and mechanical properties of TRIP steel produced by strip casting simulated in the laboratory. Mater Sci Eng A. 2016. https://doi.org/10.1016/j.msea.2016.03.106.

4. Ma Y. Medium-manganese steels processed by austenite-revertedtransformation annealing for automotive applications. Mater Sci Technol. 2017. https://doi.org/10.1080/02670836.2017.1312208.

5. Grajcar A, Kilarski A, Kozłowska A. Microstructure-property relationship in thermomechanically processed mediumMn steels with high Al content. Metals. 2018. https://doi. org/10.3390/met8110929.

6. Klueh RL, Maziasz PJ, Lee EH. Manganese as an austenite stabilizer in $\mathrm{Fe}-\mathrm{Cr}-\mathrm{Mn}-\mathrm{C}$ steels. Mater Sci Eng A. 1988. https ://doi.org/10.1016/0025-5416(88)90539-3.
7. Król M, Staszuk M, Mikuszewski T, Kuc D. Refinement effect of RE in light weight $\mathrm{Mg}-\mathrm{Li}-\mathrm{Al}$ alloys. J Therm Anal Calorim. 2018. https://doi.org/10.1007/s10973-018-7290-z.

8. Santajuana MA, Eres-Castellanos A, Ruiz-Jimenez V, Allain S, Geandier G, Caballero FG, Garcia-Mateo C. Quantitative assessment of the time to end bainitic transformation. Metals. 2019. https://doi.org/10.3390/met9090925.

9. Farahani H, Xu W, Van der Zwaag S. Prediction and validation of the austenite phase fraction upon intercritical annealing of medium Mn steels. Metall Mater Trans A. 2015. https://doi. org/10.1007/s11661-015-3081-3.

10. Steineder K, Schneider R, Krizan D, Beal C, Sommitsch C. Comparative investigation of phase transformation behavior as a function of annealing temperature and cooling rate of two medium-Mn steels. Steel Res Int. 2015. https://doi.org/10.1002/ srin. 201400551.

11. Grajcar A, Zalecki W, Burian W, Kozłowska A. Phase equilibrium and austenite decomposition in advanced highstrength medium-Mn bainitic steels. Metals. 2016. https://doi. org/10.3390/met6100248.

12. Bhadeshia HKDH. A thermodynamic analysis of isothermal transformation diagrams. Met Sci. 2013. https://doi. org/10.1179/030634582790427217.

13. Grajcar A, Zalecki W, Skrzypczyk P, Kilarski A, Kowalski A, Kołodziej S. Dilatometric study of phase transformations in advanced high-strength bainitic steel. J Therm Anal Calorim. 2014. https://doi.org/10.1007/s10973-014-4054-2.

14. Guo H, Feng X, Zhao A, Li Q, Ma J. Influence of prior martensite on bainite transformation, microstructure, and mechanical properties in ultra-fine bainitic steel. Materials. 2019. https ://doi.org/10.3390/ma12030527.

15. Navarro-Lopez A, Sietsma J, Santofimia MJ. Effect of prior athermal martensite on the isothermal transformation kinetic below $\mathrm{M}_{\mathrm{s}}$ in a low-C high-Si steel. Metall Mater Trans A. 2016. https://doi.org/10.1007/s11661-015-3285-6.

16. Gong W, Tomota Y, Harjo S, Su YH, Aizawa K. Effect of prior martensite on bainite transformation in nanobainite steel. Acta Mater. 2015. https://doi.org/10.1016/j.actamat.2014.11.029.

17. Tian J, Xu G, Zhou M, Hu H, Wan X. The effects of $\mathrm{Cr}$ and $\mathrm{Al}$ addition on transformation and properties in low-carbon bainitic steels. Metals. 2017. https://doi.org/10.3390/met7020040.

18. Caballero FG, Bhadeshia HKDH. Very strong bainite. Curr Opin Solid State Mater Sci. 2004. https://doi.org/10.1016/j. cossms.2004.09.00515.

19. Guo H, Zhou P, Zhao A, Zhi C, Ding R, Wang J. Effects of $\mathrm{Mn}$ and $\mathrm{Cr}$ on microstructure and mechanical properties of low temperature bainitic steel. J Iron Steel Res Int. 2017. https://doi. org/10.1016/S1006-706X(17)30042-0.

20. Farahani $\mathrm{H}, \mathrm{Xu} \mathrm{W}, \mathrm{Zwaag}$ S. Predicting the cooperative effect of $\mathrm{Mn}-\mathrm{Si}$ and $\mathrm{Mn}-\mathrm{Mo}$ on the incomplete bainite formation in quaternary $\mathrm{Fe}-\mathrm{C}$ alloys. Philos Mag Lett. 2018. https://doi. org/10.1080/09500839.2018.1515505.

21. Grajcar A, Kamińska M, Opiela M, Skrzypczyk P, Grzegorczyk B, Kalinowska-Ozgowicz E. Segregation of alloying elements in thermomechanically rolled medium-Mn multiphase steel. J Achiev Mater Manuf Eng. 2012;55:256-64.

22. Xiaochuan X, Chen B, Wang H, Wang L. The effect of morphology on the stability of retained austenite in quenched and partitioned steel. Scr Mater. 2013. https://doi.org/10.1016/j.scrip tamat.2012.11.003.

23. Pak JH, Bhadeshia HKDH, Larlsson L, Keehan E. Coalesced bainite by isothermal transformation of reheated weld metal. Sci Technol Weld Join. 2008. https://doi.org/10.1179/136217108X 338926. 
24. Bhadeshia HKDH, Keehan E, Karlsson L, Andren HO. Coalesced bainite. Trans Indian Inst Met. 2006;59:689-94.

25. Bhadeshia HKDH. Bainite in steels. 3rd ed. London: Institute of Materials; 1992.
Publisher's Note Springer Nature remains neutral with regard to jurisdictional claims in published maps and institutional affiliations. 